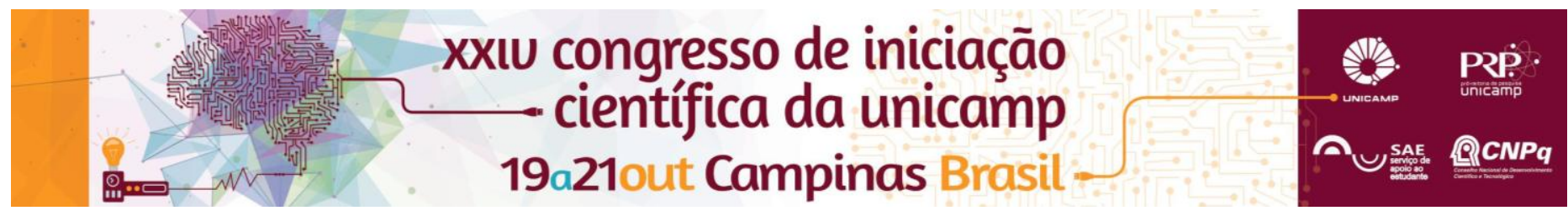

\title{
Síntese e Caracterização de Complexos Dinucleares de Íons Lantanídeos com Emissão no Infravermelho Próximo
}

\author{
William Moreno Oliva* (IC), Italo Odone Mazali (PQ), Fernando Aparecido Sigoli (PQ)
}

\begin{abstract}
Resumo
Tendo em vista os crescentes interesses no estudo da luminescência de íons lantanídeos - em especial visando seu uso no imageamento de sistemas biológicos, no tratamento de doenças e na preparação de sensores de temperatura e de oxigênio - este projeto visa a síntese e a caracterização estrutural e espectroscópica de um complexo dinuclear contendo o ligante 1,3-di(piridin-4-il)propano-1,3-dionato e os íons $\mathrm{Yb}^{\text {III }}$ e $\mathrm{Nd}^{\text {III }}$. Dadas as dificuldades experimentais encontradas e o tempo dedicado às obtenções do ligante $\beta$-dicetonato e dos aquo-complexos de partida, bem como a otimização das condições de síntese que se fez necessária, de início prezou-se aqui pela purificação e caracterização inequívoca destes precursores, mantendo-se a busca do composto proposto como objetivo último de etapas futuras.
\end{abstract}

\section{Palavras-chave}

Luminescência, Lantanídeos, Infravermelho Próximo

\section{Introdução}

Uma série de compostos dinucleares de íons lantanídeos, tendo como ligantes o ânion derivado da 2tenoiltrifluoroacetona [ $\mathrm{H}(\mathrm{tta})$, Fig. 1a], o trifenilfosfinóxido (tppo, Fig. 1b) e uma ponte intramolecular feita pelo ligante [2-(difenilfosforil)etil]difenilfosfinóxido (dppeo, Fig. 1c), foi estudada em um trabalho recente deste grupo de pesquisas $^{1}$, os quais mostraram boas estabilidades térmica e fotoquímica - motivos pelos quais julga-se este um sistema promissor, se otimizadas suas propriedades de emissão na região do infravermelho próximo (NIR). No caso do complexo heteronuclear contendo o par $\mathrm{Yb}^{\text {III/ } / \mathrm{Er}}{ }^{\mathrm{III}}$, não foi observada eficiente transferência de energia entre os ligantes e os metais, além de ter sido verificada a rápida desativação não-radiativa dos níveis emissores deste sistema.

O presente projeto de pesquisa se propôs, pois, a realizar a síntese, a caracterização estrutural e o estudo das propriedades fotoluminescentes de complexos dinucleares análogos, especialmente contendo os íons $\mathrm{Yb}^{\text {III }}$ e $\mathrm{Nd}^{\text {III }}$, mantendo-se os ligantes fosfinóxidos e permutando-se o ligante $\beta$-dicetonato de modo que a energia do nível tripleto do tripleto esteja mais próxima das energias dos níveis emissores dos íons lantanídeos escolhidos - a exemplo do derivado da 1,3-di(piridin-4-il)propano-1,3-diona [H(bppd), Fig. 1d], recém-sintetizada em um trabalho paralelo do grupo visando uma melhor transferência de energia intramolecular, a minimização das taxas de decaimento não-radiativo e a consequente intensificação da emissão dos ativadores luminescentes no infravermelho próximo.

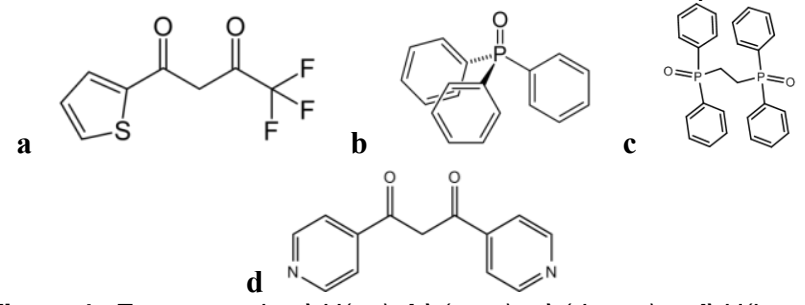

Figura 1. Estruturas de a) $H(t t a)$, b) (tppo), c) (dppeo) e d) $H(b p p d)$.

\section{Resultados e Discussão}

O ligante $\mathbf{H}(\mathbf{b p p d})$ foi sintetizado com sucesso a partir da reação entre 4-acetilpiridina e isocianato de etila, envolvendo a formação de um ânion enolato como intermediário. Este procedimento foi adaptado de metodologias utilizadas para a obtenção de compostos semelhantes ${ }^{2}$.

A partir dele, buscou-se sintetizar os complexos precursores $\left[R E(\mathrm{bppd})_{3}\left(\mathrm{H}_{2} \mathrm{O}\right)_{\mathrm{x}}\right],\left(R E^{\prime \prime \prime}=\mathrm{La}^{\prime \prime \prime}, \mathrm{Gd}^{\prime \prime \prime}, \mathrm{Yb}^{\prime \prime \prime}\right.$, $\mathrm{Nd}^{\text {III }}$ ), também por meio da adaptação de um método tradicionalmente utilizado para tal fim $^{3}$. Entretanto, esta não se mostrou totalmente eficiente e bastante dependente do $\mathrm{pH}$ do meio, o qual de fato não foi controlado durante as sínteses iniciais e levou, por exemplo, à precipitação dos respectivos hidróxidos de íons lantanídeos. A síntese se mostrou, ainda, sensível à presença de água no meio, uma vez que esta é também o agente precipitante do processo. Efetuadas as otimizações necessárias e a purificação dos aquocomplexos, procedeu-se à elucidação estrutural destes, em especial utilizando a espectroscopia vibracional no infravermelho, análise elementar e análises térmicas.

\section{Conclusões}

A determinação da estrutura e da estequiometria exatas dos complexos precursores é essencial para o andamento do projeto, visto que será necessária, por exemplo, a substituição das moléculas de água supostamente coordenadas para a obtenção dos complexos dinucleares objetivados - cujas metodologias certamente exigirão refinos experimentais similares para a realização de sínteses satisfatórias.

\section{Agradecimentos}

Agradece-se ao CNPq pela bolsa concedida, ao Instituto de Química da UNICAMP pelo uso de sua infraestrutura e por seu material humano e a CNPq, CAPES e FAPESP por financiamentos correlatos.

\footnotetext{
${ }^{1}$ Petiote, L.; Dissertação de Mestrado. Universidade Estadual de Campinas, 2015.

$\left.{ }^{2} \boldsymbol{a}\right)$ Cho, W.; et al. Synthetic Metals 175 (2013), 68-74. b) Burrows, A. D.; Frost, C. G.; et al. Chem. Comm. 46 (2010), 5067-5069.

${ }^{3}$ a) Melby, L. R.; Rose, N. J.; Abramson, E.; Caris, J. C. J. Am. Chem. Soc. 86 (1964), 5117-5125. b) Charles R. G.; Ohlmann, R. C. J. Inorg. Nucl. Chem. 27 (1965), 259-260.
} 